\title{
A violência simbólica e a dominação masculina no campo esportivo: algumas notas e digressões teóricas
}

CDD. 20.ed. 301.633

796.05

\author{
Leila SALVINI ${ }^{* * *}$ \\ Juliano de SOUZA ${ }^{* / * *}$ \\ Wanderley MARCHI J UNIOR ${ }^{* * * *}$ \\ *Universidade Federal \\ do Paraná \\ *AAsociación Latinoame- \\ ricana de Estudios Socio- \\ culturales del Deporte.
}

\section{Resumo}

No presente artigo procuramos apresentar, de um ponto de vista teórico, algumas conjecturas relacionadas ao exercício da violência simbólica e, sobretudo, da dominação masculina no campo esportivo recuperando, na medida do possivel, alguns exemplos práticos diretamente relacionados ao futebol e ao uso do corpo nos esportes. Tendo como ponto de partida para construção dos argumentos, a análise sociológica de Pierre Bourdieu, nos propomos, num primeiro momento, em apresentar brevemente a teoria dos campos e seus desdobramentos em se tratando da leitura do esporte. Num segundo momento, pretendemos avançar no tratamento da violência simbólica e dos usos legítimos do corpo como uma das formas sutis da dominação masculina reproduzida no campo esportivo.

Unitermos: Violência simbólica; Dominação masculina; Campo esportivo.

\section{Introdução}

Ao longo de sua obra o sociólogo francês Pierre Bourdieu sistematizou um conjunto de ferramentas teórico-metodológicas a fim de possibilitar o estudo da sociedade em seus mecanismos estruturais mais profundos, ou seja, no intuito de vislumbrar o dissimulado, de trazer à luz a partir de um referencial teórico rigoroso e consistente, comportamentos e configuraçōes historicamente obscurecidas, isto é, de evidenciar os elementos ocultos de dominação que se instituem nas relações sociais e mantém a estrutura das posiçóes no interior dos mais distintos campos da forma mais conservadora possível.

Colocado sob outro aparato terminológico, podemos dizer que o referido autor edifica sua obra a partir do questionamento da reprodução das desigualdades sociais e suas leis que se efetivam nas relações estruturantes da sociedade de modo a torná-las menos obscuras e intransparentes, ou seja, de mais fácil compreensão e assimilação por parte das pessoas que estão inseridas em posiçôes de desprestígio e exploração nesses espaços.

$\mathrm{Na}$ esteira, portanto, desse programa de pesquisa sobre o desvelamento de estruturas simbólicas tornadas opacas e naturalizadas no mundo social é que procuramos, no decorrer deste artigo desenvolver alguns apontamentos relacionados ao exercício da violência simbólica e, mais especificamente, da dominação masculina no campo esportivo brasileiro recuperando, na medida do possível, alguns exemplos práticos diretamente relacionados ao futebol e ao uso do corpo nos esportes.

Para tanto, valemo-nos dos recursos reflexivos da digressão teórica, com vistas de pleitear um acesso menos cartesiano e mais exploratório e imaginativo ao empreendimento sociológico de Pierre Bourdieu, procurando extrair, na medida do possível, uma série de novas entradas e possibilidades analíticas de seu referencial para pensar o esporte, o corpo e as relaçōes de gênero no futebol. O texto está dividido em duas partes. Na primeira delas, propomo-nos em apresentar a Teoria dos Campos e seus principais desdobramentos para leitura do fenômeno esportivo. Já na segunda parte, pretendemos avançar no tratamento da violência simbólica e dos usos legítimos do corpo como uma das formas sutis da dominação masculina reproduzida no campo esportivo. 


\section{A teoria dos campos e o mundo dos esportes}

Para compreender o conceito de campo, inadvertidamente devemos nos debruçar sobre o conceito de "habitus", uma vez que durante a lógica de construção dos primeiros pressupostos e argumentos que balizariam a teoria do mundo social de Pierre Bourdieu, inicialmente empreendida e ensaiada durante seus trabalhos etnológicos realizados a partir de suas experiências e constatações na região do Béarn e na sociedade cabila na Argélia colonial, o autor francês inspirado na tradição filosófica aristotélica e nos escritos de Marcel Mauss e Erwin Panofsky logrou, num primeiro momento, em sistematizar o conceito de "habitus" e posteriormente o conceito de campo, que, nesse propósito, reside sobre o próprio conceito de "habitus".

Tendo plena convicção de que o "habitus" vai além de ser conceituado, visto que o mesmo é uma categoria gerativa na Teoria dos Campos de Pierre Bourdieu, o que propomos aqui, são apontamentos que possam vir a esclarecer alguns termos essenciais presentes sobre essa noção no corpo de sua obra. De acordo com Bourdieu:

O habitus, que é princípio gerador de respostas mais ou menos adaptadas às exigências de um campo, é produto de toda a história individual, bem como através das experiências formadoras da primeira infância, de toda história coletiva da família e da classe; em particular, das experiências em que se exprime o declínio da trajetória de toda uma linhagem e que podem tomar a forma visível e brutal de uma falência ou, ao contrário, manifestar-se apenas como regressões insensíveis (Bourdieu, 2004, p.131).

Colocado nesses termos, o "habitus" funciona, portanto, como esquema de ação, de percepção, de reflexão, encarnado no corpo e na mente, de forma durável e com o contorno de disposiçōes permanentes por meio de gestos, posturas, formas de ver o mundo, de classificar a si próprio e classificar seus pares por meio de suas próprias classificaçōes. É algo adquirido e decorrente das estruturas sociais e históricas de cada um dos campos e de cada um dos agentes. Nesse propósito, o "habitus" apresenta-se ao mesmo tempo como social e individual, reportando a sistemas de classificaçōes que são evidenciados pelas posições sociais, nas quais, a estrutura objetiva de distribuição dos bens materiais e simbólicos na sociedade ocorre fundada em parâmetros de desigualdade (MARCHI JúNIOR, 2004).

Para o sociólogo brasileiro Sergio Miceli (2007), o "habitus" completa o movimento de interiorização de estruturas exteriores, ao passo que as práticas dos agentes exteriorizam os sistemas de disposiçōes incorporadas. O "habitus" é assim "[...] um corpo socializado, um corpo estruturado, um corpo que incorporou as estruturas imanentes de um mundo ou de um setor particular desse mundo, de um campo, e que estrutura tanto a percepção desse mundo como a ação nesse mundo" (Bourdieu, 1996, p.144). O "habitus" tende, portanto, a conformar e a orientar a ação, na medida em que ele próprio como produto das relações sociais assegura a reprodução dessas mesmas relaçōes objetivas que o engendram (ORTIZ, 1983).

Não obstante, é importante frisarmos que esse programa de análise das matrizes comportamentais não pode ser estruturado, segundo Bourdieu, sem considerar os estímulos externos e objetivos de determinado campo social. Desta forma, para o sociólogo, existe uma cumplicidade ontológica entre o conceito de "habitus" e o conceito e campo. Dito em outros termos, a constituição de campos relativamente autônomos se dá pela a incidência dos "habitus" nesses espaços, já que como nos ensina Bourdieu (2007b, p.102-3) o campo estrutura o "habitus" em tão presente medida que o "habitus" constitui o campo.

Mais especificamente, o que o sociólogo está sugerindo é que a análise estrutural dos campos e a análise estruturante dos "habitus" fazem parte de um mesmo projeto analítico, isto é, são leituras completamente entrelaçadas, imbricadas e penetrantes. Aí reside o perigo de se tomar mecanicamente um ou outro desses conceitos e aplicar na análise e compreensão de determinadas práticas e realidades empíricas, como se fosse possível, segundo a perspectiva sociológica de Pierre Bourdieu, isolar os mecanismos estruturais que constituem a sociedade de uma análise mais específica das disposiçóes estruturalmente inscritas nos corpos, ou melhor, incorporadas pelos agentes e vice-versa (SouZA \& MARCHI JúnIOR, 2010).

Para Bourdieu todo campo se caracteriza por agentes dotados em traços gerais de um mesmo "habitus" e justamente por isso é que o habitus vem a ser entendido ao longo de sua obra como uma necessidade tornada virtude, visto que as disposições para ação incorporadas ao mesmo tempo em que são necessárias para se entrar no jogo também asseguram distinções e prestígio. Já o campo, por sua vez, distingue-se como um "locus" social de lutas, disputas e concorrência entre os dominantes - detentores de poder de determinado campo - frente aos dominados que tentam se estabelecer nessa estrutura a partir da utilização de estratégias que 
lhe permitam ter acesso aos objetos de interesse e as posições distintas e legítimas do campo em questão. Vejamos nas palavras do próprio autor:

Um campo é um espaço social estruturado, um campo de forças - há dominantes e dominados, há relaçôes constantes, permanentes de desigualdade, que se exercem no interior desse espaço - que é também um campo de lutas para transformar ou conservar esse campo de forças. Cada um, no interior desse universo, empenha em sua concorrência com os outros a força (relativa) que detém e que define sua posição no campo e, em conseqüência, suas estratégias (Bourdieu, 1997, p.57).

Além, portanto, de ser um "locus" de concorrência e relações mais ou menos acirradas pelo monopólio das tomadas de decisão e pela disputa dos capitais (fichas) em jogo, os campos possuem algumas propriedades específicas e gerais de funcionamento. Como lei específica, podemos citar o fato de cada campo produzir sua própria "illusio" (sentido do jogo), o que nos permite afirmar, em conformidade com Bourdieu, a existência de tantas variedades de capitais em jogo como campos propriamente ditos. De acordo com o sociólogo francês, os espaços sociais ao se constituírem como campos, produzem formas de interesse específicas que, por sua vez, podem ser consideradas como desinteresse no ponto de vista dos demais campos de produção material e simbólica (Bourdieu, 2007b, p.149).

Nesse propósito, Bourdieu confere um tratamento sociológico aos campos como "locus" relativamente autônomos, sendo que no conjunto de sua obra o campo artístico foi constatado como o mais autônomo de todos os campos e o campo midiático como o mais dependente das demandas externas. No entanto, Bourdieu também ressalva ao sistematizar leis gerais de funcionamento dos campos, que espaços sociais distintos em seu grau de autonomia possuem normas de funcionamento invariantes, o que, por sua vez, nos possibilita aplicar o aprendizado da estrutura de determinado campo, na interrogação e interpretação das lutas de outros campos.

De acordo com MARCHI JúNIOR (2004), dentro da particularidade de cada campo, há formas de disputas, lutas e competições, sendo que vislumbramos em cada uma delas a especificidade das relações entre o "novo" - que tenta garantir o direito de participação - e o dominante - que defende o monopólio objetivando excluir a concorrência.

Vale frisarmos que é exatamente nessa linha de raciocínio que Bourdieu preconiza uma forma particular de entender o esporte moderno. $\mathrm{E}$ isso, dentre outros fatores, porque, denomina de campo o espaço social ocupado pelos fenômenos esportivos, no qual se atribuem posições compatíveis com o capital social, econômico ou cultural de cada agente. Além disso, esses agentes a partir de disputas no seio das estruturas buscam a hegemonia de determinadas práticas além, é claro, do acúmulo de uma distinção social conforme o seu potencial de poder simbólico, isto é, do poder de transformar ou então conservar os princípios objetivos que estruturam e organizam o mundo social.

Dessa forma, para que uma Sociologia do Esporte possa, de fato, se constituir, é imprescindível que se pense o esporte e o espaço de suas práticas como um sistema no qual cada elemento recebe seu valor distintivo. Segundo Bourdieu (2004), para compreender o esporte é preciso conhecer a posição que ele ocupa no espaço dos esportes por meio de indicadores como: a distribuição dos praticantes segundo sua posição no espaço social; a distribuição de diferentes federações; o número de adeptos, sua riqueza, as características sociais dos dirigentes, bem como, o tipo de relação com o corpo que ele favorece ou exige, isto é, se existe o contato direto ou se esse contato ocorre por intermédio de instrumentos. Por fim, “[...] é preciso relacionar esse espaço de esportes como o espaço social que se manifesta nele. Isso a fim de evitar os erros ligados ao estabelecimento de uma relação direta entre um esporte e um grupo que a intuição comum sugere" (Bourdieu, 2004, p.208).

Respaldados por essa leitura, podemos dizer, portanto, que a distância social se traduz muito bem na lógica do esporte quanto ao contato corporal das modalidades e a distinção que lhes é concebida e conferida pelos agentes dotados dos esquemas de percepção e do monopólio do juízo estético. No entanto, o sociólogo francês (BOURDIEU, 2004) ressalta que para evitar um julgamento imediato, no sentido de se relacionar mecanicamente a prática esportiva com a posição social do praticante, é preciso analisar as diferentes atividades esportivas com o espaço das posições sociais que ocupam os agentes envolvidos.

Devemos notar que é justamente por conta desse entendimento, que Bourdieu percebe e avança no tratamento do esporte na condição de um fenômeno inserido em um sistema mercadológico de práticas e consumos que se liga intimamente com outras formas de consumo em geral, ou seja, que está inserido de forma muito peculiar e articulada no espectro da relação entre as leis de oferta e procura na sociedade capitalista.

Ao se apropriar desse referencial para subsidiar a leitura do esporte no Brasil, mais precisamente, 
do voleibol brasileiro, MARCHI JÚNIOR (2004, p.49) descreve que no âmbito da oferta encontra-se um espaço para os programas esportivos, no qual se caracterizam as propriedades intrínsecas e técnicas do esporte. Já no âmbito da procura, destaca-se o espaço das disposições esportivas - entendidas como "habitus" marcados pelas respectivas posiçôes sociais - que, em determinada instância, são definidas pela particularidade do estado atual da oferta.

Dentre essas especificidades, o campo das práticas esportivas também se constitui como um "locus" de disputa pela imposição da definição legítima da prática esportiva e da função legítima das atividades esportivas, ou seja, a legitimação do amadorismo contra o profissionalismo, do esporte prática contra o esporte espetáculo, do esporte de elite - distintivo - e o esporte popular - de massa. Além disso, é no interior de um espaço próprio de lutas que se encontra a legitimidade das funções do esporte enquanto atividade propriamente esportiva, que requer a definição do corpo legítimo e do uso legítimo do corpo no esporte (BouRdieu, 1983).
Até aqui procuramos rapidamente trabalhar alguns elementos formadores do "habitus" e constituidores dos campos, tendo por referência a cumplicidade ontológica entre as duas noçōes/ ferramentas analíticas. Propusemos-nos também em problematizar e apontar a forma com que o "habitus" - disposições corporais e mentais de classificação - se articula ao universo dos esportes. Para esse desiderato, entretanto, resgatamos alguns elementos teórico-analíticos que constituem o programa bourdieusiano para uma Sociologia do Esporte.

Feitas essas incursōes teóricas preliminares que nos permitem sugerir que os campos são por excelência lugares construídos por via da violência e da dominação dimensionada como "habitus" e, portanto, como forma duradoura e autorizada de ver o mundo, pretendemos nas próximas linhas avaliar a especificidade desse processo tal como retomado no interior do campo esportivo, especialmente, no sentido de conjecturar que esse "locus", por mais questionável que seja, é um lugar de exercício da dominação masculina e da violência simbólica.

\section{A violência simbólica e os usos legítimos do corpo como forma da dominação masculina no campo esportivo}

Tomando por base as lutas no interior dos campos, em especial no campo esportivo - o qual, nesse artigo, não é de nossa pretensão se deter de forma aprofundada no sentido de descrevê-lo historicamente e localizá-lo na estrutura social mais ampla conforme sugeriu Bourdieu em seus programas de pesquisa -, pretendemos nos concentrar, nesse momento, no tratamento da violência simbólica que institui fundamentos ocultos de dominação no espaço dos esportes de contato, dentre eles o futebol, visando localizar a dominação masculina na legitimação dos corpos como fim na determinação de práticas esportivas.

Segundo Bourdieu, a dominação não é o efeito direto e simples da ação exercida por um conjunto de agentes sobre outros (dominantes "versus" dominados), mas o efeito indireto de um conjunto complexo de açōes que se engendram na estrutura do campo por meio do qual se exerce a dominação frente aos demais (Bourdieu, 1996). Tal dominação não é evidente, e sim camuflada, a tal ponto que muitas vezes os que a sofrem não a percebem. De acordo com o sociólogo francês (1997, p.22): "A violência simbólica consiste em uma violência que se exerce com a cumplicidade tácita dos que a sofrem e também, com freqüência, dos que a exercem, na medida em que uns e outros são inconscientes de exercê-la ou de sofrê-la".

Deste modo, a violência simbólica define-se, num primeiro momento, como uma violência dissimulada, o que, diga-se de passagem, lhe confere poderes particulares e eficácia específica. Tal violência não pode ser usada independentemente, pois não é um tipo distinto de violência. Ela é violência física mascarada e, por conseguinte, invisível e esquecida. Conforme afirma Terray (2005, p.304): "Esse tipo de violência tem por efeito, estabelecer a legitimidade de um discurso, de decisão, de um agente ou uma instituição, entretanto, as relações de força que originam a violência simbólica, são desconhecidas".

TERRAY (2005) prossegue em sua análise, dizendo que a função da violência simbólica é reprimir a arbitrariedade. No entanto, para o autor, ela conserva o traço indelével daquilo que combate, pois, permanece fundada numa relação de força cujo caráter arbitrário é irredutível. O autor reforça que dessa maneira a violência simbólica assemelha-se a uma prisão invisível, sem paredes nem portas e finaliza dizendo que "[...] se a violência simbólica atrai um poder suplementar porque nela a violência 
é mascarada, ao contrário, sua força diminui quando sua máscara lhe é arrancada e ela é forçada a aparecer de cara limpa" (Terray, 2005, p.307).

Acrescentemos a essa análise o fato de que a violência simbólica evoca o que é legítimo e aceitável por meio de imposições tácitas. Devemos, além disso, notar que o reconhecimento e aceitação do que é legítimo para um campo em específico, normalmente não se aplica da mesma maneira a outro. Entretanto, o processo é idêntico: o reconhecimento da legitimidade se enraíza no acordo imediato entre as estruturas incorporadas, tornadas inconscientes.

Por sua vez, esse acordo pré-reflexivo potencialmente explica a facilidade, de fato, espantosa e recorrente com que os dominantes impõem sua dominação (BourdiEu, 2007a). É justamente nessa leitura e constatação apontada por Bourdieu que prosseguiremos com nosso argumento afirmando que "[...] a dominação não é apenas uma dominação de classe ou de grupos. É também uma dominação masculina” (SAINT Martin, 2005, p.330).

Transportando, portanto, o conceito de legitimidade, às nuances da dominação masculina, a qual se pauta em leis andrógenas, BOURDIEU (2007b) alega que o paradoxo não está nas diferenças visíveis do corpo feminino ou masculino que se dá partindo de uma visão androcêntrica e sim na instituição de características biológicas como sendo duas essências sociais hierarquizadas, que se legitimam e se naturalizam frente aos dominados (mulheres). Dito de outro modo, as diferenças biológicas são evocadas e mobilizadas no sentido de fundamentar as diferenças sociais e, por conta disso, elementos que engendram a distinção do ser masculino do ser feminino são enaltecidos e as semelhanças obscurecidas.

A partir dessa arquitetura teórica, podemos mencionar, de um lado, o uso social do corpo como forma de distinção entre os sexos e, de outro, a padronização das condutas e a utilização de objetos-signos a fim de retratar o que é aceito e desejável. Transpondo essas constatações de Bourdieu esmiuçadas no texto "A dominação masculina" para pensarmos o universo esportivo, podemos dizer que não é conferida a mulher - representada pela delicadeza do seu corpo, gestos e pela submissão de seus atos - uma prática legítima de esportes que possam ferir esses atributos, enquanto, a validação da masculinidade, em muitos momentos, é proporcionada pelo esporte - em especial esportes de contato - onde elementos de virilidade frequentemente são trazidos à tona e reafirmados.

Tal qual apontado anteriormente, que a distinção também se instaura em elementos de dominação masculina, visualizamos, a partir das contribuiçôes de VEBLEN (1983) no final do século XIX, que os esportes eram reservados aos homens como demonstração de tempo livre e do consumo conspícuo, enquanto às mulheres eram reservadas atividades menos valorativas e, invariavelmente, não honrosas. Em direção mais ou menos similar, DunNING e MAGUIRE (1997, p.340), por sua vez, explicam que: "[...] o esporte tende a representar uma importante fonte de experiência da validação da masculinidade a ser percebida como uma barreira contra a feminilização e a emasculação".

Deste modo, podemos entrever que, durante o processo de construção de uma história ocidental dos esportes, foram indicadas as mulheres práticas esportivas que reforçassem caracteres estéticos, "feminis" e de eugenização. Essa leitura, por sua, vez, é reforçada por BouRdieu (1983) ao mencionar o caráter higienista do esporte para o público feminino. Segundo o autor, as mulheres, por conta do desconhecimento e mascaramento em que estão fundadas as relaçôes sociais de desigualdade entre os sexos, "[...] submetem-se às normas que definem o que deve ser o corpo, não só na sua configuração perceptível, mas também na sua atitude, na sua apresentação, etc." (Bourdieu, 1983, p.201).

Importa, nesse propósito, também lembrar que as mulheres durante muito tempo foram excluídas de assuntos sérios, que envolvessem honrarias e méritos, e, dessa forma, lhes restou desenvolverem preocupaçóes de cuidado com sua imagem corporal em uma dimensão talvez proporcionalmente "superior" quando comparadas aos homens. Além disso, a herança de sociedades menos diferenciadas, nas quais as mulheres eram tratadas como meios de troca, permitindo aos homens acumular capital social e simbólico e, nos dias atuais, a reprodução do capital simbólico do grupo doméstico expressa por sua aparência - maquiagens, trajes, porte se constitui, sem dúvida, como bons indicativos das leis de reprodução das relações tradicionais entre os sexos nas sociedades em que vivemos (Bourdieu, 2007a).

Some-se a essa compreensão o fato de que determinados atributos como a delicadeza, a feminilidade, a maternidade - reforçados maciçamente durante o período da revolução burguesa no Brasil onde os cuidados com o corpo feminino se davam no sentido de prepará-las para geração de fillhos saudáveis, bem como à manutenção de sua beleza - logram ainda em permanecer arraigadas à figura feminina, que existe somente enquanto corpo para os outros (BOURDIEU, 2007a).

Tais elementos, por sua vez, colidem com a conduta que se espera na prática de esportes que tem no contato direto entre seus oponentes, a base de 
sua lógica intrínseca de oferta e consumo, como no caso do futebol. Ou seja, a legitimidade corporal feminina construída histórica e culturalmente não é a mesma legitimidade corporal exigida para a prática do futebol de alto rendimento. Nesse contexto, a mulher-esportista acaba incorporando ações de outros espaços sociais para o espaço esportivo como forma de legitimar sua feminilidade, adentrar e se estabelecer na lógica do futebol. Esse reforço de características femininas em um espaço de dominação masculina pode ser vislumbrado e entendido como estratégia de entrada e/ou de manutenção nesse "locus".

Se as jogadoras incorporam às suas ações práticas dentro de campo - de acordo com as possibilidades que o esporte oferece - elementos que remetam aos já entendidos como pertencentes ao ser feminino (como cabelos compridos, unhas pintadas, uniformes mais ajustados) reforçam o "ideal" feminino e reforçam a luta pela legitimidade de um corpo que incorporou tanto as características do esporte (como a força, a resistência, o combate) quanto as características entendidas socialmente como femininas (como a sensualidade, a beleza, o cuidado etc.).

Essa estratégia é também utilizada pelos meios de comunicação que além das habilidades esportivas anseiam pela espetacularização dos corpos femininos no esporte. Nessa esteira, os dirigentes também incorporaram ao seu discurso e açôes esse novo investimento na feminilização dos corpos das jogadoras, pois, estando próximo da centralidade esperada e construída socialmente para o gênero feminino a possibilidade de obter patrocínios de empresas que queiram vincular sua marca ao futebol das mulheres, aumenta.

Contudo, como o corpo feminino no futebol nem sempre se constrói de maneira a legitimar, ou a exaltar, os atributos de feminilidade em um espaço onde as características dominantes são as masculinas, a sexualidade dessas jogadoras é questionada. Entendendo o corpo como a vitrine do "habitus", quanto mais distanciada da noção de centralidade do gênero feminino uma jogadora se apresentar, ou apresentar seu corpo, seus gestos, sua fala, o modo de agir, menor é sua legitimidade como mulher. Do mesmo modo, quando mais próxima dessas características as jogadoras se apresentarem em campo e as veicularem à sua imagem, maior é a aproximação com a centralidade de gênero e logo maior também é a legitimidade corporal feminina.

Cabe, portanto, reiterarmos que ao adentrarem em tais redutos historicamente tidos como masculinos e carregados de simbolismos atrelados à masculinidade, a feminilidade das atletas é posta em dúvida pela sociedade. Em certos casos, ela é até posta em dúvida por outras mulheres e esta, inclusive, é uma reação típica dos grupos excluídos na medida em que interiorizaram "o carisma coletivo" daqueles que estão estabelecidos no espaço futebolístico há mais tempo, ou seja, os homens (ELIAS \& SCOTSON, 2000).

Esse pensamento das mulheres (de forma preconceituosa com seus pares), por conseguinte, muito possivelmente se trata de um produto e fruto da incorporação das relações de poder e das divisões do trabalho sexual e da divisão sexual do trabalho expressas nas oposições fundadoras e estruturantes da ordem simbólica, conforme bem demonstrou e argumentou Bourdieu (2007a). No que se diz respeito ao futebol, essas impressões são ainda reforçadas no comentário de GOELLNER (2000):

Criado, modificado, praticado, comentado e dirigido por homens, o futebol parece pertencer ao gênero masculino, como parece também ser de seu domínio o julgamento de quem podel deve praticá-lo ou não. É quase como se à mulher coubesse a necessidade de autorização masculina para tal (p.81).

Se considerarmos, portanto, a noção de dominação masculina somada às lutas que se instauram no interior dos espaços esportivos não teremos muita dificuldade em visualizar que as mulheres, de fato, ocupam posição de dominadas no "locus" futebolístico. Ademais, é necessário lembrar que a própria violência simbólica originada pela dominação masculina toma forma nos questionamentos que pairam sobre a legitimidade do corpo feminino nesse "locus", promovendo certa instabilidade ou insegurança por parte das jogadoras.

Talvez não seja nenhum exagero defender a ideia de que o futebol no Brasil é um espaço de reprodução, afirmação e dominação masculina, e que as mulheres que adentram esse espaço são conduzidas inconscientemente - até mesmo para ampliar suas chances de acesso aos capitais em jogo - a incorporar algumas características do "habitus" do futebol masculino. Por outro lado, também ocorre dessas agentes negociarem suas ações práticas no espaço do futebol a partir do ideal de "habitus" feminino socialmente construído e reproduzido em outros espaços sociais, o que, apenas, contribui para estender ou mesmo preservar a dominação masculina já estabelecida em outros contextos e circunstâncias.

Estaríamos então diante de uma identidade ambígua do futebol feminino brasileiro? Muito possivelmente. E o que é mais curioso e preocupante: uma identidade que por estar sobejamente fundada nos dois pilares acima descritos, acaba por encerrar 
as mulheres-futebolistas em uma posição de duplo desconforto social. Se, por um lado, essas mulheres incorporam o "habitus" do futebol masculino, são então estigmatizadas e tem sua sexualidade colocada socialmente a prova. Se, por outro lado, preservam ou então buscam se apresentar mais femininas em jogo são desacreditadas quanto sua performance em um esporte que historicamente tem sido associado às ideias de força e virilidade.

De modo mais incisivo, diríamos então que essa identidade ambígua do futebol feminino brasileiro é construída basicamente sob dois espectros: um que visa atender as necessidades físicas do jogo, no sentido de provar que as mulheres também possuem habilidades que atendam as prerrogativas do futebol; e o segundo que consiste em "provar" que mesmo munidas de habilidades esportivas de um esporte pré-determinado como masculino, as jogadoras mantêm determinados atributos de feminilidade em consonância com o entendimento social e cultural construído ao longo dos tempos.

É sempre bom reiterarmos que tal posição ambígua destinada às mulheres no "locus" do futebol repousa, dentre outras coisas, na instabilidade corporal. Essa última, por sua vez, se assenta na noção naturalizada, e por isso tão mais eficaz e duradoura, de que as mulheres não são suficientemente legítimas para praticarem um esporte considerado como masculino, ao passo que, ao praticarem de maneira satisfatória não apresentam ações que as legitime como mulheres (dentro de um único ideal construído e fomentado cultural e socialmente). Não é de se estranhar, portanto, que os espaços esportivos que as mulheres venham a dominar - o que em definitivo não parece ser o que ocorre no caso do futebol brasileiro - sejam justamente aqueles que reforçam sua beleza e não comprometem seriamente os seus atributos de feminilidade.

Em suma, o que queremos apontar com essa argumentação é que as leis de reprodução social, pautadas em elementos biológico-sociais de dominação masculina, colocam a mulher em permanente estado de insegurança com seu próprio corpo, ou seja, em constante necessidade de existir primeiramente pelo e para o olhar do outro. Acresçase a essa compreensão que o corpo das jogadoras de futebol, por um lado, está frente a "libertaçôes" oriundas da auto-percepção corporal fomentada pela prática esportiva e, de outro lado, está sujeito a aprovações masculinas construídas e sedimentadas como pontos de vista historicamente sexistas.

$\mathrm{Na}$ condição, portanto, de violência simbólica que atua de forma naturalizada e que tem tanto mais eficácia social quanto os agentes menos tenham consciência disso, essas leis de reprodução sexistas rapidamente mencionadas e conjecturadas nesse artigo, são reforçadas ainda por mecanismos midiáticos que veiculam uma imagem de mulheratleta atrelada aos ideais de beleza física e aos cuidados com o corpo em detrimento às habilidades esportivas e às atuações performáticas.

Nesse particular, BOURDiEu (2007b) ressalta que a mulher-atleta - pensamos aqui, por exemplo, na jogadora de futebol - tem uma auto-percepção corporal diferenciada, pois, visualiza o seu corpo para si, incorporando as categorias construídas do ponto de vista masculino e dominante de modo que as relações de dominação passam a assumir formas naturais, tal como respirar ou andar. Por sua vez, esse reforço das estruturas tradicionais da relação entre os sexos no interior do espaço social perpassa o campo esportivo e adentra outras profissóes consagradas historicamente como masculinas, nas quais, a mulher precisa, muitas vezes, estar mais bem preparada para se equivaler ao trabalho dos homens, o que, em última análise, não lhes garante que não serão vítimas dessa estrutura das relações sexuais que atingem duplamente e de forma naturalizada a homens e mulheres.

À guisa de fechamento, ressaltamos que nosso objetivo nesse artigo não foi esgotar o debate em torno das questões suscitadas, mas, ao invés disso, lançar algumas "provocações teóricas" e conjecturas de modo a contribuir para com o estabelecimento de uma reflexão sobre as relações de gênero e sexo no esporte a partir do pensamento sociológico de Pierre Bourdieu, ou, mais precisamente, de sua teoria das relações de gênero expressa, sobretudo, no livro "A dominação masculina” - uma teoria que apesar de tardia na sistematização, sempre esteve presente, sob a forma de "insights" e sob o crivo da preocupação do sociólogo francês em explicar como e de que forma são reproduzidas e conformadas as estruturas tradicionais e de desigualdade, em seu ambicioso projeto de elaboração de uma teoria geral da sociedade.

Feito esse breve parêntese, devemos frisar que no decorrer do texto procuramos basicamente problematizar que os diferentes espaços sociais ou campos são orientados e constituídos por lutas entre os "estabelecidos" e os "novos". Grosso modo, o engendramento dessas lutas se dá por meio de fundamentos ocultos de dominação, dentre os quais, a violência simbólica: violência silenciosa, porém árdua, que se realiza sem a percepção de quem sofre e, muitas vezes, de quem a utiliza como forma de impor sutilmente 
sua dominação. Dito em outros termos, trata-se de um elemento que funciona como engrenagem do campo de maneira a manter a reprodução social das crenças, por meio da incorporação legítima ("habitus") de cada agente e da posição social - e de gênero - que ocupa na estrutura que está inserido.

A propósito, a posição social dos agentes na estrutura estabelecida no interior dos mais distintos campos pode variar de acordo com diversos meios de classificação, ou seja, através de lucros de pertencimento econômico, político e simbólico. Outra forma de se estabelecer essa lógica classificatória se constitui a partir das disposições sexuais dos agentes, na instância das leis andrógenas que visam legitimar os corpos e suas funções com base em discernimentos e determinações de cunho predominantemente masculino. Nesse contexto, o corpo feminino só obtém legitimidade como tal quando submetido ao enquadramento das leis sociais sexistas fundamentadas em algumas características tidas como essenciais para uma melhor afirmação das mulheres, quais sejam, a delicadeza e a feminilidade.

Além disso, a noção histórico-cultural - fomentada exclusivamente pelo olhar masculino - de que os atributos de feminilidade inscritos nos corpos devem permear as práticas esportivas, acabam por organizá-las de formas específicas e legítimas, nas quais algumas dessas práticas vêm a reproduzir o ser feminino, enquanto outras, possivelmente por não reforçarem as referidas características "feminis" enfrentam "barreiras" generificadas e "preconceituosas" no campo. Deste modo, o futebol constitui-se um "locus" sócio-esportivo de lutas e conflitos que impõe um "universo de incertezas" tanto para a mulher inserida no futebol quanto para a sociedade mais ampla que avalia tais ajustes, tendo em vista que esse esporte é no nosso país, em muitas instâncias, a afirmação exclusiva de masculinidades.

Por conseguinte, esse "universo de incertezas" em que as mulheres futebolistas são, com frequência, socializadas, resulta num emaranhado de possibilidades e de barreiras que tem no corpo (enquanto "habitus") sua principal vitrine. Assim sendo, se essas mulheres se apresentam em campo de modo muito "feminino", são vistas pelos agentes dominantes como incapazes de jogar futebol, e se incorporam características do futebol - reduto por excelência da masculinidade hegemônica - ao seu "habitus", essas mesmas mulheres têm sua "feminilidade" desacretidada.

Nesse sentido, o preconceito de gênero frente às mulheres que jogam futebol ou que então praticam esportes estabelecidos como masculinos, pode ser pensado como violência simbólica, a qual, por sua vez, se dá no sentido de fazer crer e reproduzir crenças, nas quais, os corpos, em especial o corpo feminino, são veiculados como objeto de consumo no processo de mercantilização do esporte. Dessa maneira, se constitui um espaço esportivo diferencial e ao mesmo tempo tradicional na qual os esportes de contato ou esportes honoríficos ostentam a nobreza do ser masculino e reforçam a delicadeza e submissão feminina.

Como última observação a ser anotada neste texto, é importante então ser ressaltado que a distinção e a legitimação nos esportes não se reportam tão somente em destacar a acepção econômica das práticas no sentido clássico e burocrático, mas sim, em evidenciar que a distinção simbólica entre as várias modalidades esportivas socialmente aceitas e difundidas entre os diferentes sexos, tem o corpo e as performances corporais como principal "vitrine de exibição" da incorporação ou ainda da manutenção hegemônica de diferentes "habitus". Dito de outra forma, a aceitação social do uso legítimo dos corpos encontra-se pré-determinado por funções e ações inerentes a cada sexo ou papel sexual. Nesse caso, as leis sexistas de reprodução estrutural ao legitimarem, por exemplo, os ideais estéticos e de beleza de uma mulher, legitimam seu corpo, os usos que são feitos do mesmo, e, portanto, as práticas esportivas "afinadas" e "desafinadas" com essas condições. 


\begin{abstract}
Symbolic violence and male domination in sport field: some theoretical notes and digressions

In the present article, we aimed to develop, from a theoretical point of view, some conjectures linked to the exercise of symbolic violence and, more specifically, of male domination on sports field recovering, as far as possible, some practical examples directly linked to soccer and the use of body on sports. Having as an initial point element to arguments construction the sociological analysis of Pierre Bourdieu, we proposed, at a first time, to briefly present the theory of fields and its developments considering the sports reading. In a second time, we aimed to advance on the treating of symbolic violence and legitimate body uses as one of the subtle ways of male domination reproduced on sports field.
\end{abstract}

UnITERMS: Symbolic violence; Male domination; Sport field.

\title{
Resumen
}

La violencia simbólica y la dominación masculina en el campo deportivo: algunas notas y digresiones teóricas

En este trabajo se presenta un punto de vista teórico, algunas conjeccturas sobre el ejercicio de la violencia simbólica y, especialmente, de la dominación masculina en el campo deportivo recuperando, en la medida de lo posible, algunos ejemplos prácticos directamente relacionados con el fútbol y con el uso del cuerpo en los deportes. Teniendo como punto de partida para la construcción de los argumentos, la análisis sociología de Pierre Bourdieu, se propone, en un primer momento, presentar brevemente la teoria de los campos y sus desdobramentos en se tratando de la lectura del deporte. En un segundo momento, tenemos la intención de avanzar en el tratamiento de la violencia simbólica y los usos legítimos del cuerpo como una de las formas sutiles de dominación masculina reproduzida en el campo deportivo.

Palabras Clave: Violencia simbólica; Dominación masculina; Campo deportivo.

\section{Referências}

BOURDIEU, P. A dominação masculina. Rio de Janeiro: Bertrand Brasil, 2007a. A economia das trocas simbólicas. São Paulo: Perspectiva, 2007b.

Coisas ditas. São Paulo: Brasiliense, 2004.

Questóes de sociologia. Rio de Janeiro: Marco Zero, 1983.

Razóes práticas: sobre a teoria da ação. Campinas: Papirus, 1996.

Sobre a televisão. Rio de Janeiro: Jorge Zahar, 1997.

DUNNING, E.; MAGUIRE, J. As relações entre os sexos no esporte. Revista Estudos Feministas, Florianópolis, v.5, n.2, p.321-48,1997.

ELIAS, N.; SCOTSON, J. Os estabelecidos e os outsiders. Rio de Janeiro: Zahar, 2000.

GOELLNER, S. Pode a mulher praticar o futebol? In: CARRANO, P.C. Futebol, paixão e política. Rio de Janeiro: DP\&A, 2000. p.79-94.

MARCHI JÚNIOR, W. “Sacando” o voleibol. São Paulo: Hucitec, 2004.

MICELI, S. Introdução: a força do sentido. In: BOURDIEU, P. A economia das trocas simbólicas. São Paulo: Perspectiva, 2007. p.VII-LXI.

ORTIZ, R. A procura de uma sociologia da prática. In: ORTIZ, R. (Org.). Pierre Bourdieu: sociologia. São Paulo: Ática, 1983. p.7-29. SAINT MARTIN, M. Uma inflexível dominação? In: ENCREVÉ, P; LAGRAVE, R. (Orgs.). Trabalhar com Pierre Bourdieu. Rio de Janeiro: Bertrand Brasil, 2005. p.327-35. 
SALVINI, L.; SOUZA, J . \& MARCHI J ÚNIOR, W.

SOUZA, J.; MARCHI JÚNIOR, W. Por uma sociologia reflexiva do esporte: consideraçôes teórico-metodológicas a partir da obra de Pierre Bourdieu. Revista Movimento, Porto Alegre, v.16, n.1, p.293-315, 2010.

TERRAY, E. Proposta sobre a violência simbólica. In: ENCREVÉ, P; LAGRAVE, R. (Orgs.) Trabalhar com Pierre Bourdieu. Rio de Janeiro: Bertrand Brasil, 2005. p.303-8.

VEBLEN, T. A teoria da classe ociosa: um estudo econômico das instituições. São Paulo: Abril Cultural, 1983.

\begin{tabular}{r|l} 
ENDEREÇO & \\
Leila Salvini & Recebido para publicação: 24/ 10/2011 \\
R. Curitiba, 222 & Revisado: 02/02/2012 \\
89870-000 - Pinhalzinho - SC - BRASIL & Aceito: 04/05/2012 \\
e-mail: leila.salvini@hotmail.com & \\
& \\
\hline
\end{tabular}

410 • Rev. bras. Educ. Fís. Esporte, São Paulo, v.26, n.3, p.401-10, jul./ set. 2012 